\title{
Synthesis of Activated Carbon from Rice Husk Using Microwave Heating Induced $\mathrm{KOH}$ Activation
}

\author{
Tuan Dung Nguyen*, Jung-In Moon*, Jeong-Hwan Song** and Taik-Nam Kim***广 \\ *Department of Materials Science and Engineering, Graduate School of PaiChai University, Daejeon 302-735, Korea \\ **Department of Information and Electronic Materials Engineering, PaiChai University, Daejeon 302-735, Korea
}

(Received June 1, 2012 : Received in revised form June 13, 2012 : Accepted June 14, 2012)

\begin{abstract}
The production of functional activated carbon materials starting from inexpensive natural precursors using environmentally friendly and economically effective processes has attracted much attention in the areas of material science and technology. In particular, the use of plant biomass to produce functional carbonaceous materials has attracted a great deal of attention in various aspects. In this study the preparation of activated carbon has been attempted from rice husks via a chemical activation-assisted microwave system. The rice husks were milled via attrition milling with aluminum balls, and then carbonized under purified $\mathrm{N}_{2}$. The operational parameters including the activation agents, chemical impregnation weight ratio of the calcined rice husk to $\mathrm{KOH}(1: 1,1: 2$ and 1:4), microwave power heating within irradiation time (3-5 min), and the second activation process on the adsorption capability were investigated. Experimental results were investigated using XRD, FT-IR, and SEM. It was found that the BET surface area of activated carbons irrespective of the activation agent resulted in surface area. The activated carbons prepared by microwave heating with an activation process have higher surface area and larger average pore size than those prepared by activation without microwave heating when the ratio with $\mathrm{KOH}$ solution was the same. The activation time using microwave heating and the chemical impregnation ratio with $\mathrm{KOH}$ solution were varied to determine the optimal method for obtaining high surface area activated carbon $\left(1505 \mathrm{~m}^{2} / \mathrm{g}\right)$.
\end{abstract}

Key words activated carbon, rice husk, microwave, KOH, BET.

\section{Introduction}

Recently, activated carbon has known as its large porous surface area and controllable pore structure. Activated carbons are carbonaceous materials and the materials starting from cheap natural precursors that can be produced by physical and chemical activation. The significant things are the high surface area and complex pore structure resulting from physical or chemical activation processes. The commonly used precursors to prepared activated carbon are bituminous coal, ${ }^{1-3)}$ wood, ${ }^{4-6)}$ coconut shell, ${ }^{7-9)}$ polymers, ${ }^{10,11)}$ and so on. However, rice husk is one of the most popular material with low cost. In some reports, activated carbons were prepared from rice husks by chemical activation with $\mathrm{KOH}, \mathrm{NaOH}, \mathrm{Na}_{2} \mathrm{CO}_{3}, \mathrm{ZnCl}_{2}$, and so on, at different temperatures for various times. ${ }^{2}{ }^{13)}$ The previous researches have demonstrated the ability of rice husk-based activated carbon for many metal ions and organic molecules from aqueous phase adsorption.

Activated carbon, by its wonderful structure, has been applied in various industries for several years: it is used for the separation of gases, recovery of solvent and re-

Corresponding author

E-Mail : tnkim@pcu.ac.kr (T. -N. Kim) moval of organic pollution. ${ }^{14)}$ The applications of activated carbons are also expanded, such as super-capacitors, electrodes and gas storage, ${ }^{15-17)}$ which require the activated carbons containing a higher surface area. The activated carbon structure properties have been demonstrated to be effective for removal of a wide variety of inorganic ${ }^{18-20)}$ and organic ${ }^{21,22)}$ pollutants dissolved in aqueous media, or from gaseous environment. ${ }^{23)}$

Activated carbons have been prepared by many synthesis methods such as carbonization process, chemical agent activation, microwave heating. The use of alkali hydroxides such as sodium hydroxide $(\mathrm{NaOH})$ and potassium hydroxide $(\mathrm{KOH})$ as activating agents for the production of microporous activated carbon had attracted great interest due to the valuable properties of the materials produced by this process. For preparation of activated carbons, conventional heating method is usually adopted. Recently, microwave heating technology has been applied to fabricate activated carbons due to its heating rapidly and uniformly. The main reason for the use of microwave is that microwave power is a predominant factor affecting the adsorption uptake capacity and carbon yield. Enhancing microwave power led to increase of adsorption uptake, possibly ascribed to the combined effect of internal and volumetric heating responsible for the expansion of carbon 
structure.

Actually, as far as we know, there are few reports on the preparation of activated carbon by a combined chemical activation and microwave heating. ${ }^{24)}$ The primary objective of this study was to produce activated carbon adsorbents from rice husk by $\mathrm{KOH}$ as chemical activation and microwave heating, and then attempt the effect of the high surface area activated carbon prepared by a combined chemical activation and microwave heating.

\section{Experimental Procedure}

In this study, the rice husks (RH) was supplied by the Hyunduk industry production (Korea) as raw materials. They were washed with DI water in the ultrasonic cleaner to remove dirt and other contaminants present in them and then dried in the dry oven at about $60-70^{\circ} \mathrm{C}$ for 24 hours. Then, the dried RH was milled by the attrition milling with alumina balls (Ø $2 \mathrm{~mm}$ ). Settings for the attrition milling operate $600 \mathrm{rpm}$ for 1 hour. The milled samples were sieved through different size sieves. In this work, the particle size of less than $425 \mu \mathrm{m}$ was selected for further pretreatment. After that, the experiment was carried out carbonization for the samples. In particular, the sieved samples were tipped into an alumina boat and then put inside the tube furnace. In order to perform carbonization process, heat treatment was carried out under purified $\mathrm{N}_{2}$ with a flow ratio of $300 \mathrm{ml} / \mathrm{min}$ for 2 hours at $700-800^{\circ} \mathrm{C}$. The black calcined $\mathrm{RH}$ was obtained by carbonization process.

The next step was chemical activation for black calcined $\mathrm{RH}$. In the present work, $\mathrm{KOH}$ was chosen as the chemical activating agent. $\mathrm{KOH}$ solution is very effective to remove in the organics and they dissolve the silica which contains in the RH. Based on the main objective to get the activated carbon, the black calcined RH was carried out soaking treatment in $\mathrm{KOH}$ solution. In chemical impregnation, the weight ratio of black calcined $\mathrm{RH}$ to $\mathrm{KOH}$ was corresponding to $1: 1,1: 2$ and $1: 4$. For example, in case of ratio of black calcined $\mathrm{RH}: \mathrm{KOH}$ is $1: 2,1$ gram of black calcined RH was dispersed and soaked in $\mathrm{KOH}$ solution with 2 gram $\mathrm{KOH}$ in $100 \mathrm{ml}$ DI water. The $\mathrm{RH}$ soaked in $\mathrm{KOH}$ solution were stirred and dried until paste state by the hot plate at $60^{\circ} \mathrm{C}$ and then the paste samples were dried in the dry oven at $60^{\circ} \mathrm{C}$ for several hours.

The dried paste was carried out heating by microwave irradiation (90-800 W) for 3-5 minutes. The samples were washed in ultrasonics machine and then dried for several hours before preparing activation in the tube furnace again. The second activation was performed at different temperature in the range of 700 to $900^{\circ} \mathrm{C}$ for 3 hours. The final step was washing the samples in $100 \mathrm{ml}$ DI water at $100^{\circ} \mathrm{C}$, and filtering. The activated carbon (AC) have got

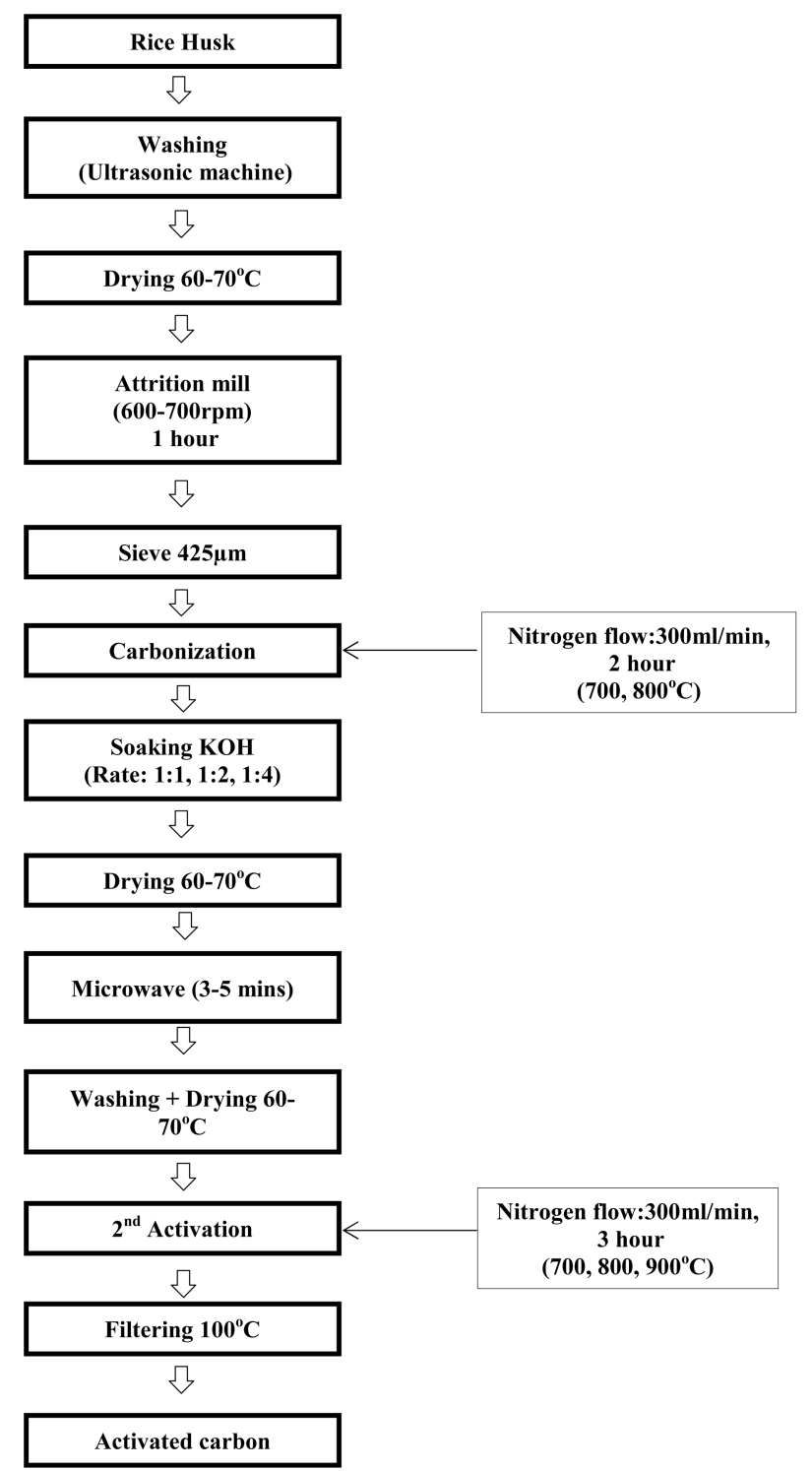

Fig. 1. Schematic representation of processing steps for the synthesis of activated carbon derived from rice husk.

after drying of the filtered char. All of the processing steps for the synthesis of activated carbon derived from rice husk were clearly exhibited in the schematic in Fig. 1.

The activated carbon was characterized to determine crystal structure by measurement of X-ray diffraction (XRD, CuK $\alpha$ radiation $(\lambda=0.15418 \mathrm{~nm}), \mathrm{D} 1 \mathrm{w}$, Shimadzu, Japan) over the $2 \theta$ range from $20^{\circ}$ to $80^{\circ}$ at a scan rate of $2 \% \mathrm{~min}$. Besides, particle size and morphology were observed by scanning electron microscope for observation SEM (Sirion, FEI, Netherland). Fourier-transform infrared (FT-IR) spectra were recorded with a FT-IR Frontier from PerkinElmer. The transmittance of pellets consisted of $10 \mathrm{mg}$ of the powder sample and $1 \mathrm{~g} \mathrm{KBr}$, and was measured in a wavenumber interval of $800-2000 \mathrm{~cm}^{-1}$. Specific surface area determinations were performed by 
Table 1. Experimental parameters and porous structure parameters of activated carbon derived from rice husk in activation condition at $700^{\circ} \mathrm{C}$ for $3 \mathrm{~h}$.

\begin{tabular}{|c|c|c|c|c|c|c|}
\hline Sample & $\begin{array}{l}\text { Carbonization } \\
\text { Temp. }\left({ }^{\circ} \mathrm{C}\right)\end{array}$ & Char : $\mathrm{KOH}$ & $\begin{array}{c}\text { Microwave } \\
\text { heating (min) }\end{array}$ & $\begin{array}{l}\text { Activation } \\
\text { Temp. }\left({ }^{\circ} \mathrm{C}\right)\end{array}$ & $\begin{array}{c}\text { Average } \\
\text { Pore size }(\AA)\end{array}$ & $\begin{array}{c}\text { Micropore } \\
\text { Volume }\left(\mathrm{cm}^{3} / \mathrm{g}\right)\end{array}$ \\
\hline AC7117 & \multirow{2}{*}{700} & \multirow{2}{*}{$1: 1$} & 0 & \multirow{2}{*}{700} & 29.6 & 0.35 \\
\hline AC7117-3 & & & 3 & & 27.4 & 0.34 \\
\hline AC7127 & \multirow{2}{*}{700} & \multirow{2}{*}{$1: 2$} & 0 & \multirow{2}{*}{700} & 22.0 & 0.41 \\
\hline AC7127-3 & & & 3 & & 30.9 & 0.37 \\
\hline AC7147 & \multirow{2}{*}{700} & \multirow{2}{*}{$1: 4$} & 0 & \multirow{2}{*}{700} & 22.6 & 0.58 \\
\hline AC7147-3 & & & 3 & & 63.4 & 0.49 \\
\hline
\end{tabular}

Table 2. Experimental parameters and porous structure parameters of activated carbon derived from rice husk in various activation conditions at $800^{\circ} \mathrm{C}$ and $900^{\circ} \mathrm{C}$ for $3 \mathrm{~h}$.

\begin{tabular}{|c|c|c|c|c|c|c|}
\hline Sample & $\begin{array}{l}\text { Carbonization } \\
\text { Temp. }\left({ }^{\circ} \mathrm{C}\right)\end{array}$ & Char: $\mathrm{KOH}$ & $\begin{array}{c}\text { Microwave } \\
\text { heating (min) }\end{array}$ & $\begin{array}{l}\text { Activation } \\
\text { Temp. }\left({ }^{\circ} \mathrm{C}\right)\end{array}$ & $\begin{array}{c}\text { Average } \\
\text { Pore size }(\AA)\end{array}$ & $\begin{array}{c}\text { Micropore } \\
\text { Volume }\left(\mathrm{cm}^{3} / \mathrm{g}\right)\end{array}$ \\
\hline AC7118 & \multirow{2}{*}{700} & \multirow{2}{*}{$1: 1$} & 0 & \multirow{2}{*}{800} & 25.2 & 0.43 \\
\hline AC7118-3 & & & 3 & & 28.5 & 0.32 \\
\hline AC7128 & \multirow{3}{*}{700} & \multirow{3}{*}{$1: 2$} & 0 & 800 & 21.4 & 0.72 \\
\hline AC7128-3 & & & 3 & 800 & 22.3 & 0.42 \\
\hline AC7129-3 & & & 3 & 900 & 29.4 & 0.39 \\
\hline AC7148 & \multirow{3}{*}{700} & \multirow{3}{*}{$1: 4$} & 0 & & 23.3 & 0.77 \\
\hline AC7148-3 & & & 3 & 800 & 25.7 & 0.34 \\
\hline AC7148-5 & & & 5 & & 19.9 & 0.55 \\
\hline
\end{tabular}

the surface areas, average pore size and micropore volumes of the activated carbons using the Brunauer-Emmett-Teller (BET) method with an adsorption meter of $\mathrm{N}_{2}$ (model ASAP 2010 micromeritics).

\section{Results and Discussion}

One thing to admit that specific surface area parameter (BET) is an important factor to estimate porous character and micropore structure. Thus, in this study, various experimental parameters were prepared and labeled as described in Table 1 and Table 2. Table 1 and Table 2 gives information on porous structure parameters of activated carbon derived from $\mathrm{RH}$ in various conditions. It is clearly realized effective factors on the specific surface area $\left(\mathrm{S}_{\mathrm{BET}}\right)$ such as weight ratio of char: $\mathrm{KOH}$, microwave heating process and activation temperatures.

\subsection{Characteristic of activated carbon}

The structural parameters and features of the activated carbons were obtained from the XRD analysis. The XRD results from activated carbons synthesized by activating at $700^{\circ} \mathrm{C}$ for $3 \mathrm{~h}$ using a combined soaking in various $\mathrm{KOH}$ weight ratio and microwave heating for 3 minutes are shown in Fig. 2. The XRD pattern of activated carbon basically appears the non-crystalline form. In the vicinity of $2 \theta \approx 25-26^{\circ}$, the XRD pattern was shown wide width

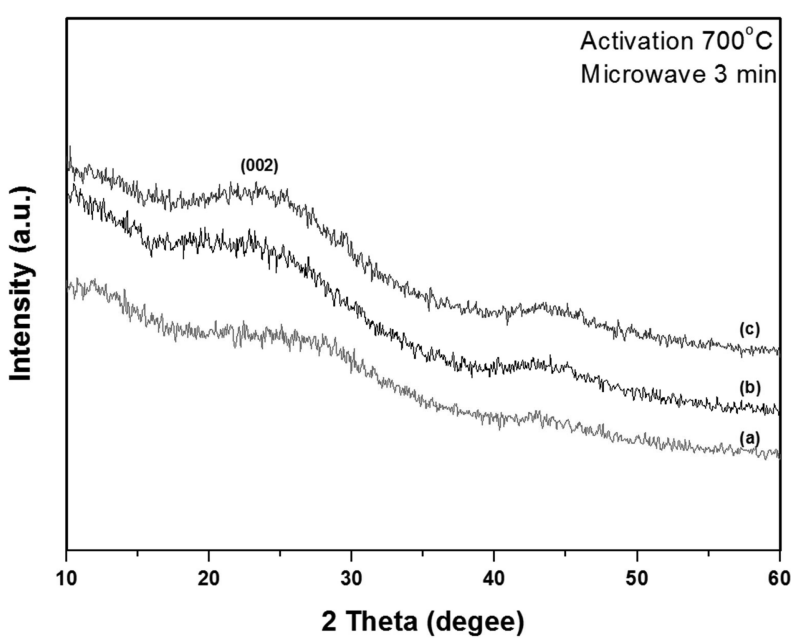

Fig. 2. XRD patterns of activated carbon synthesized by activating at $700^{\circ} \mathrm{C}$ for 3 hours using a combined soaking in various $\mathrm{KOH}$ weight ratio and microwave heating for 3 minutes: (a) 1:1 (AC71173), (b) 1:2 (AC7127-3) and (c) 1:4 (AC7147-3).

and asymmetric peak. The XRD pattern of $2 \theta \approx 26^{\circ}$, corresponding to (002) peak, was observed to appear with increasing concentration of $\mathrm{KOH}$ solution. Interestingly, only the diffraction peaks typical of activated carbon were seen in the XRD pattern and no indication of impurities is observed. This indicates the effectiveness and also the significance of the treatment with a base solution. Phase 

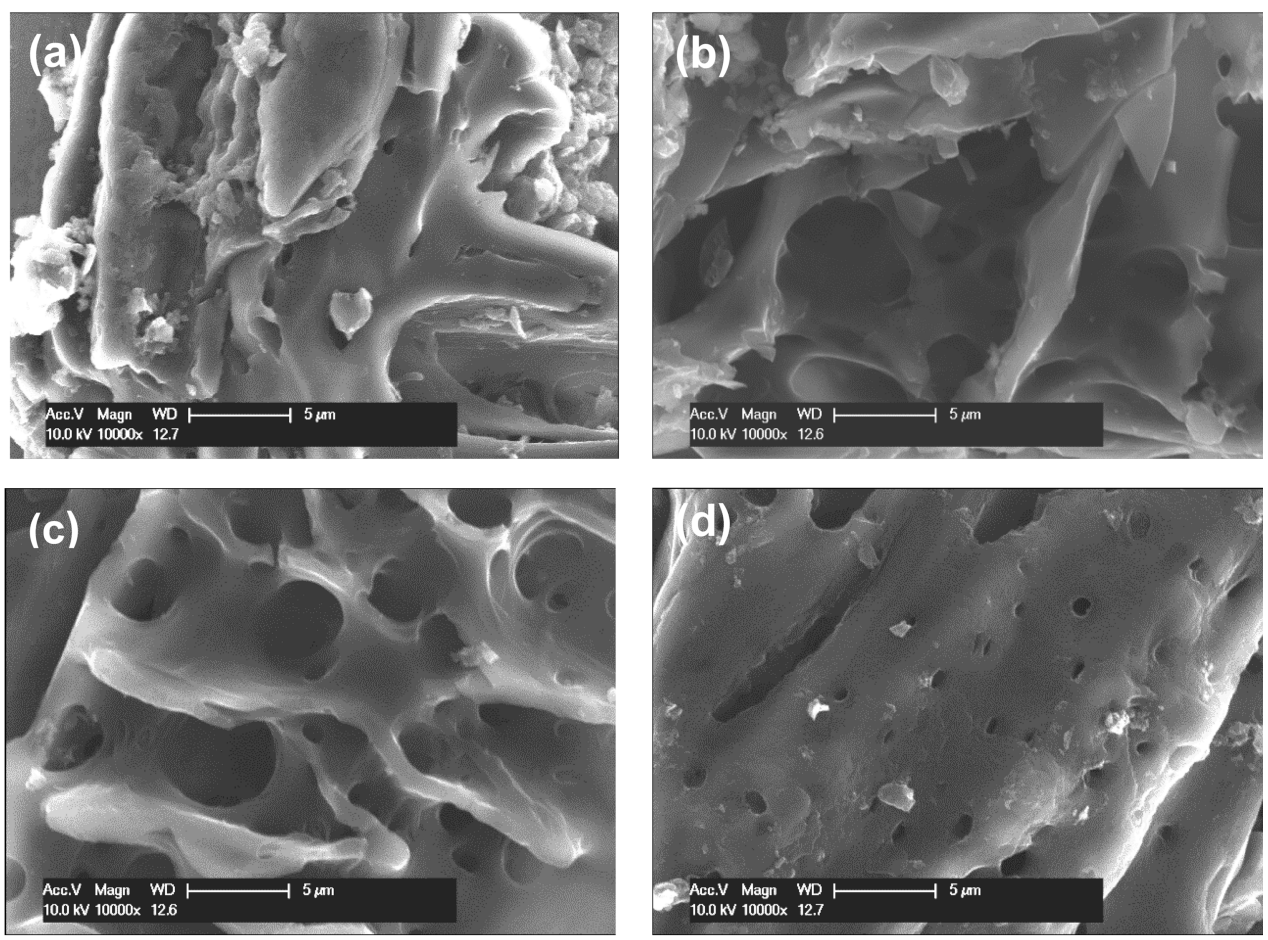

Fig. 3. SEM photographs of activated carbon synthesized by activating at $700^{\circ} \mathrm{C}$ for 3 hours using a combined soaking in various $\mathrm{KOH}$ weight ratio and microwave heating for 3-5 minutes: (a) AC7117-3, (b) AC7127-3, (c) AC7147-3 and (d) AC7148-5.

structure of activated carbon was affected by ratio of char : $\mathrm{KOH}$.

Scanning electron microscopy (SEM) micrographs of activated carbon synthesized by activating at $700^{\circ} \mathrm{C}$ for 3 hours using a combined soaking in various $\mathrm{KOH}$ weight ratio and microwave heating for 3-5 minutes are given in Fig. 3. Based on the SEM images, the structure of activated carbon was porous with many pores. Although applying the microwave system with longer irradiation time (5 minutes) as shown in Fig. 3(d) sample, the activated carbon structure was not more porous as the samples structure which was activated for 3 minutes microwave. This result was shown clearly in Fig. 3(d) and the above Table 1. With increasing concentration of $\mathrm{KOH}$ solution, average pore size increases. However, in Fig. 3(d) sample obtained by longer irradiation time of microwave, average pore size decreases.

Fig. 4 shows XRD patterns of activated carbon nanopowders synthesized by activating at $800^{\circ} \mathrm{C}$ for $3 \mathrm{~h}$ using a combined soaking in various $\mathrm{KOH}$ weight ratio and microwave heating for 3 minutes. The only different point is intensity of peak as the effect of activation temperature on the structure of activated carbon. When the weight ratio of char: $\mathrm{KOH}$ is $1: 1$, the intensity of peak of activated carbons increase with increasing activation temperature. The two broad peaks are observed at $26^{\circ}$ and $44^{\circ}$ typical of activated carbons, corresponding to (002) and (101) in the XRD pattern, respectively (JCPDS 12-

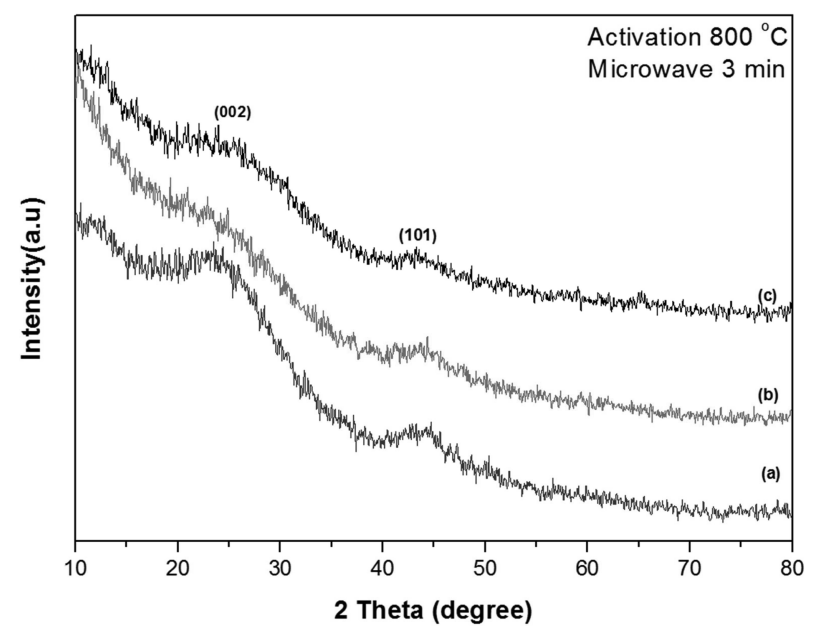

Fig. 4. XRD patterns of activated carbon synthesized by activating at $800^{\circ} \mathrm{C}$ for 3 hours using a combined soaking in various $\mathrm{KOH}$ weight ratio and microwave heating for 3 minutes: (a) 1:1 (AC71183), (b) 1:2 (AC7128-3) and (c) 1:4 (AC7148-3).

0212). Especially, partly crystallization was observed in the sample soaking ratio of 1:1 $\mathrm{KOH}$ solution combining activation at $800^{\circ} \mathrm{C}$ (AC7118-3) as shown in the Fig. 4. However, no main peak is observed for the samples with increasing concentration of $\mathrm{KOH}$ solution probably due to an effect on the structure of activated carbon by a variation of the internal structure.

Fig. 5 shows the SEM photographs of activated carbon synthesized by activating at $800^{\circ} \mathrm{C}$ for 3 hours using a 

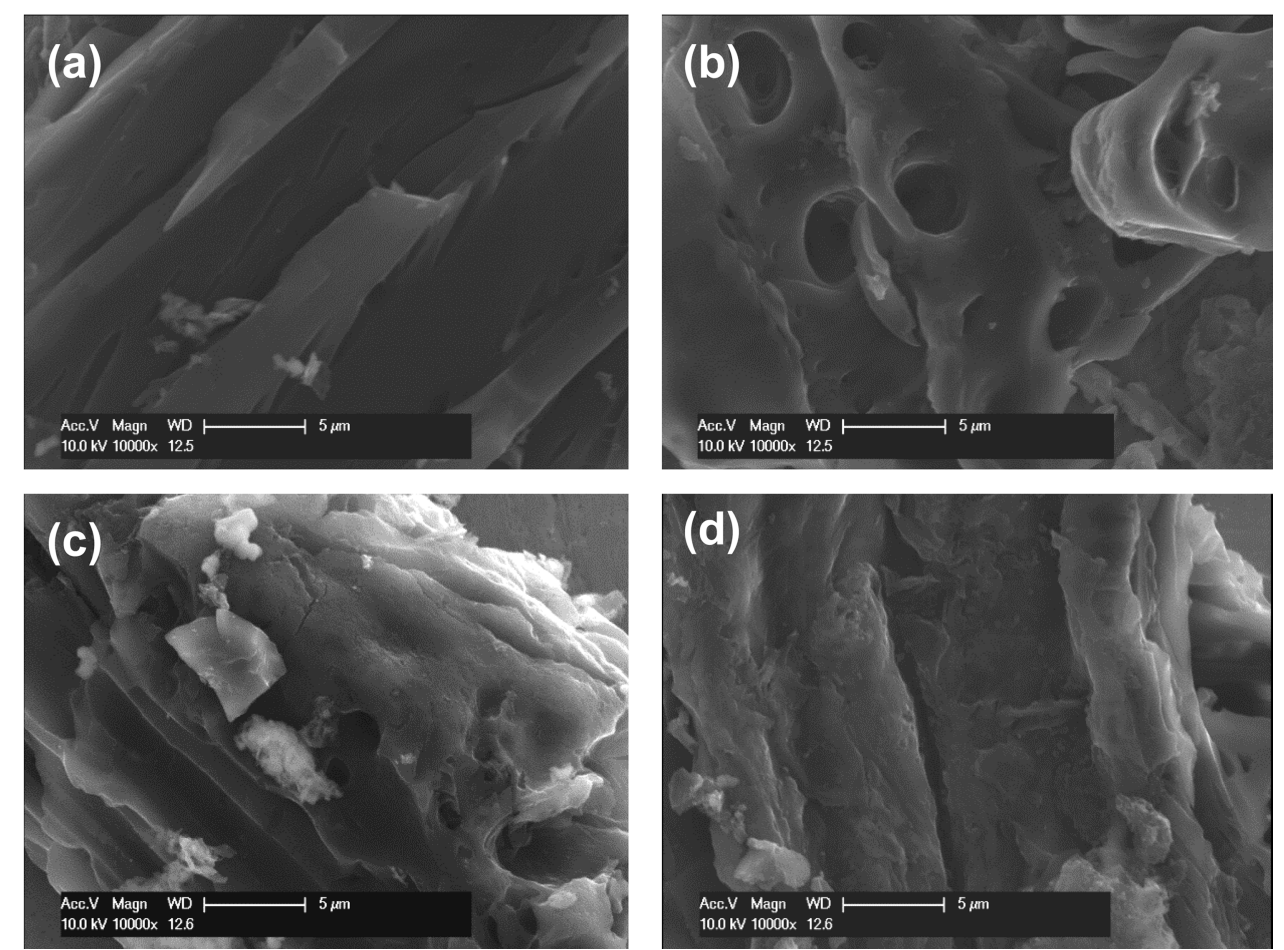

Fig. 5. SEM photographs of activated carbon synthesized by activating at $800^{\circ} \mathrm{C}$ for 3 hours using a combined soaking in various $\mathrm{KOH}$ weight ratio and microwave heating for 3-5 minutes: (a) AC7118-3, (b) AC7128-3, (c) AC7148-3 and (d) AC7129-3.

combined soaking in various $\mathrm{KOH}$ weight ratio and microwave heating for 3 minutes. With increasing concentration of $\mathrm{KOH}$ solution, average pore size decreases. Also, the activated carbons treated at the higher activa-

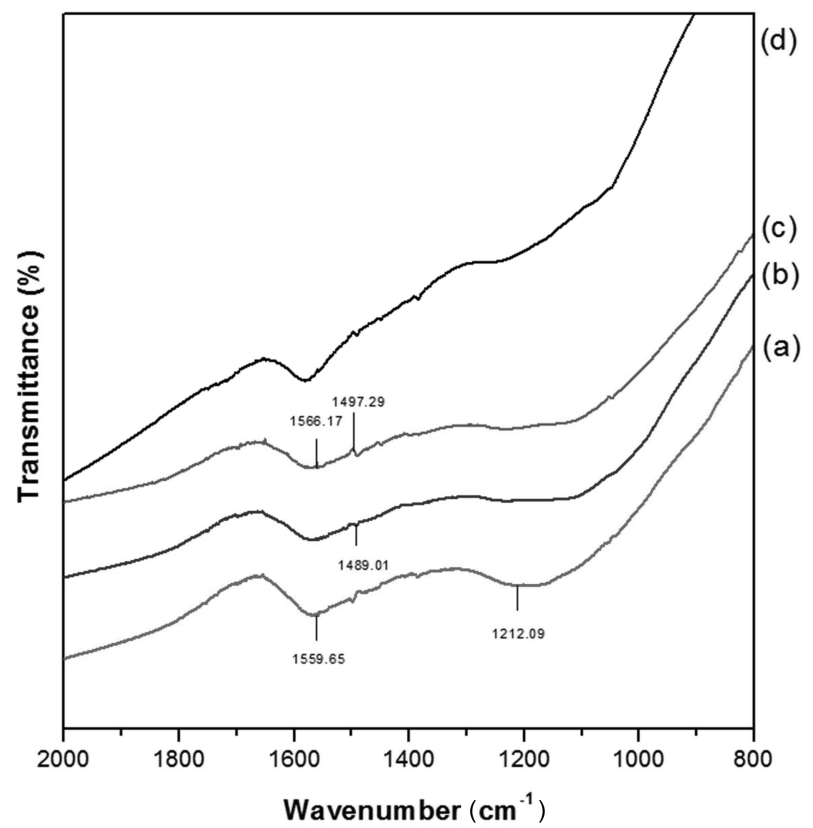

Fig. 6. FTIR spectra of activated carbon synthesized by various activating temperature for 3 hours using a combined soaking in various $\mathrm{KOH}$ weight ratio and microwave heating for 3 minutes: (a) AC71273, (b) AC7147-3, (c) AC7128-3 and (d) AC7148-3. tion temperature tend to be dense compare with the sample of Fig. 3.

The surface of carbon materials is, in general, rich in a variety of surface functional groups among which the CO type groups are predominant. To know the specific type of functional groups present on the surface, the activated carbon materials were analyzed by FT-IR analysis.

The FT-IR spectra of the activated carbon synthesized by activating from $700^{\circ} \mathrm{C}$ and $800^{\circ} \mathrm{C}$ for 3 hours using a combined soaking in various $\mathrm{KOH}$ weight ration and microwave heating for 3 minutes were shown in Fig. 6. It can be noticed that for all the carbons the peaks at $1212.08 \mathrm{~cm}^{-1}$ is observed and their reason is the $\mathrm{CO}$ group (stretch of $\mathrm{C}=\mathrm{O}$ ). In addition, the creation of bands at $1489.01,1497.29,1566.17$ and $1559.65 \mathrm{~cm}^{1}$ can be results of the ionic form of carboxylic groups. ${ }^{25)}$

\subsection{Effect of activation temperatures and microwave heating process}

The second activation process was carried out at range of 700 to $900^{\circ} \mathrm{C}$ for 3 hours under purified $\mathrm{N}_{2}$ gas. According to the afore-mentioned Table 1, it is clearly seen that porous properties of activated carbons changed with the change of activation temperatures.

Fig. 7 shows the effect of activation temperatures on specific surface area BET $\left(\mathrm{S}_{\mathrm{BET}}\right)$ parameters of the activated carbon samples. As can be seen, the specific surface areas of the activated carbons at $800^{\circ} \mathrm{C}$ had higher than 


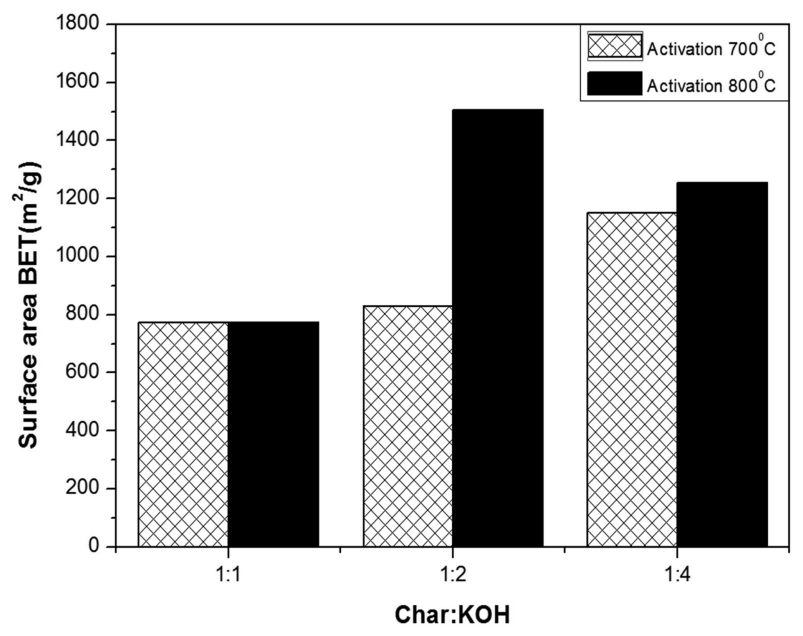

Fig. 7. Diagram representation of effect of activation temperatures $\left(700\right.$ and $800^{\circ} \mathrm{C}$ ) on BET surface areas of activated carbon.

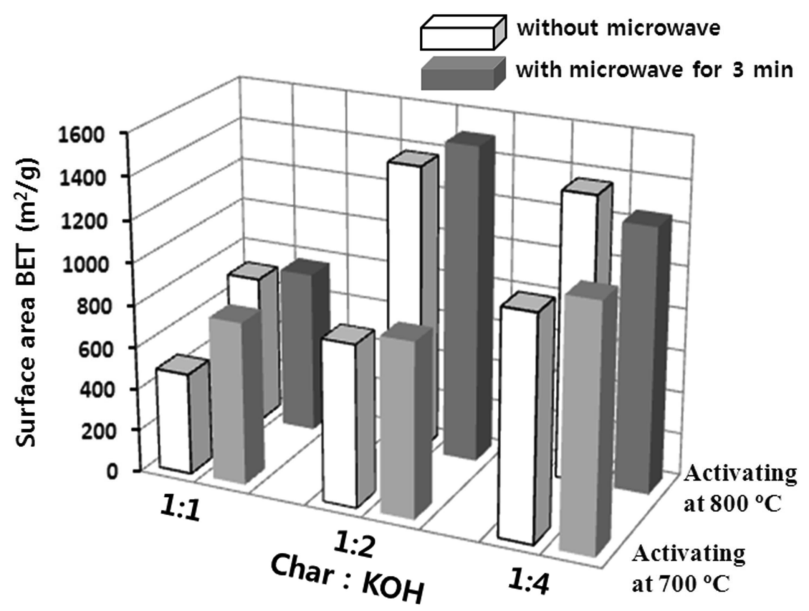

Fig. 8. Diagram representation of effect of microwave heating process on surface areas BET of activated carbon activating at 700 and $800^{\circ} \mathrm{C}$.

those of the activated carbons at $700^{\circ} \mathrm{C}$. However, in case of activation at $700^{\circ} \mathrm{C}$, the samples tended to increase $\mathrm{S}_{\mathrm{BET}}$ according to rate of char : $\mathrm{KOH}$. This result is one of the evidences that express the influence of concentration of $\mathrm{KOH}$ solution on $\mathrm{S}_{\mathrm{BET}}$ of activated carbon. In the activated carbons at $800^{\circ} \mathrm{C}$, the highest $\mathrm{S}_{\mathrm{BET}}$ for sample that soaked with $\mathrm{KOH}$ according to ratio of 1:2 was 1505 $\mathrm{m}^{2} / \mathrm{g}$. However, the $\mathrm{S}_{\mathrm{BET}}$ decreased to $1254 \mathrm{~m}^{2} / \mathrm{g}$ corresponding to ratio of 1:4 (char: $\mathrm{KOH})$. In general, at higher activation temperature, specific surface area of activated carbon tends to increase significantly.

The present work also attempted synthesis activated carbon without microwave. These samples have surface areas that were shown on the Table 1 and Table 2 without microwave heating.

Based on the above diagram in Fig. 8, it is clearly seen that the use of microwave to heat the samples before carrying out the second activation affected surface area of activated carbon. In particular, the synthesis of activated carbon using microwave heating before activation $700^{\circ} \mathrm{C}$ according to the ratio of corresponding char: $\mathrm{KOH}$ got the positive results making the samples that have $\mathrm{S}_{\mathrm{BET}}$ higher than the synthesized samples without microwave. Especially, the sample AC7117-3 (microwave 3 minutes) has $\mathrm{S}_{\mathrm{BET}}\left(775 \mathrm{~m}^{2} / \mathrm{g}\right)$ was double than the sample AC7113 (without microwave) with the lowest surface area value $\left(482 \mathrm{~m}^{2} / \mathrm{g}\right)$. At $700^{\circ} \mathrm{C}$ activation, $\mathrm{S}_{\mathrm{BET}}$ value of activated carbon went up corresponding to rate of precursor samples with $\mathrm{KOH}$ (1:1, 1:2 and 1:4). This result, one more time, apparently indicated the effect of rate of soaking char with $\mathrm{KOH}$ on $\mathrm{S}_{\mathrm{BET}}$ of activated carbon.

Likewise, Fig. 8 showed the diagram that illustrated the effect of microwave heating process on BET surface areas of activated carbon activating at $800^{\circ} \mathrm{C}$. BET surface area of these samples tended to increase from condition soaking ratio of 1:1 with $\mathrm{KOH}$ and reached peak of the highest $\mathrm{S}_{\mathrm{BET}}$ at condition 1:2 before decreasing at condition 1:4. However, the sample that was heated by microwave in condition 1:2 having the highest $\mathrm{S}_{\mathrm{BET}}$. In addition, Table 1 also indicated that the microwave heating affected pore size of active carbon. If we estimate and compare in the same of soaking $\mathrm{KOH}$ : char condition, the average pore size of the samples that were synthesized using microwave treatment were more bigger than that of other synthesized samples without microwave. One thing to note that the sample AC7147-3 (rate with $\mathrm{KOH} \mathrm{1:4,} \mathrm{activation}$ temperature $700^{\circ} \mathrm{C}, 3$ minutes microwave treatment) has the maximum average pore size just over $63 \AA$.

\section{Conclusion}

In this study, the activated carbon were synthesized by chemical activation method and microwave heating with various activating temperatures and ratio of char: $\mathrm{KOH}$, the phase structure of activated carbon was investigated and observed. The XRD pattern of activated carbon basically appears the non-crystalline form at the activation temperature $700^{\circ} \mathrm{C}$, however, partly crystallization was observed in the sample soaking ratio of 1:1 $\mathrm{KOH}$ solution combining activation at $800^{\circ} \mathrm{C}$.

In summary, microwave heating method can provide an efficient way to prepare activated carbons with high surface area. It is interesting to admit that the activated carbons prepared by microwave heating method present higher $\mathrm{S}_{\mathrm{BET}}$ compared to those prepared by method without microwave when $\mathrm{KOH} /$ char ratio is the same.

The $\mathrm{S}_{\mathrm{BET}}$ increases with the increase in $\mathrm{KOH} /$ char ratio in the range of $1: 1$ and 1:2, and then decreases with the further increase in the ratio for each heating method at rate of $1: 4$ in the case of activation $800^{\circ} \mathrm{C}$. When activation 
process was carried out at $700^{\circ} \mathrm{C}$, surface areas tend to rise significantly corresponding to increase in the ratio of char : $\mathrm{KOH}$. There is relation between activation temperature, ratio of soaking char and $\mathrm{KOH}$ solution and microwave heating. The research would attempt more the effect of microwave time as well as activation temperature in the future. The change of surface and internal structure were exhibited clearly by the above evidence.

\section{Acknowledgement}

This research work was supported by Development project based on co-operation with Republic of KoreaSouth East Asia (Viet Nam) of the National Research Foundation of Korea (NRF), which is funded by the Ministry of Education, Science and Technology (K2100 200 1988-11B1200-10310).

\section{References}

1. E. N. El Qada, S. J. Allen and G. M. Walker, Chem. Eng. J., 124, 103 (2006).

2. B. Y. Jibril, R. S. Al-Maamari, G. Hegde, N. Al-Mandhary and O. Houache, J. Anal. Appl. Pyrol., 80, 277 (2007).

3. C. Zhang, D. Long, B. Xing, W. Qiao, R. Zhang, L. Zhan, X. Liang and L. Ling, Electrochem. Comm., 10, 1809 (2008).

4. J. N. Sahu, J. Acharya and B. C. Meikap, Bioresource Tech., 101, 1974 (2010).

5. S. Yorgun, N. Vural and H. Demiral, Microporous Mesoporous Mater., 122, 189 (2009).

6. J. Acharya, J. N. Sahu, B. K. Sahoo, C. R. Mohanty and B. C. Meikap, Chem. Eng. J., 150, 25 (2009).

7. K. Yang, J. Peng, C. Srinivasakannan, L. Zhang, H. Xia and X. Duan, Bioresource Tech., 101, 6163 (2010).

8. G. Afrane and O. W. Achaw, Bioresource Tech., 99, 6678
(2008).

9. S. Guo, J. Peng, W. Li, K. Yang, L. Zhang, S. Zhang and H. Xia, Appl. Surf. Sci., 255, 8443 (2009).

10. M. Seredych, E. Deliyanni and T. J. Bandosz. Fuel, 89, 1499 (2010).

11. Z. Zhu, A. Li, L. Yan, F. Liu and Q. Zhang. J. Colloid Interface Sci., 316, 628 (2007).

12. Y. Chen, Y. Zhu, Z. Wang, Y. Li, L. Wang, L. Ding, X. Gao, Y. Ma and Y. Guo, Adv. Colloid Interface Sci., 163, 39 (2011).

13. K. Y. Foo and B. H. Hameed, Bioresource Tech., 102, 9814 (2011).

14. N. Bagheri and J. Abedi, Chem. Eng. Res. Des., 87, 1059 (2009).

15. A. Yuan and Q. Zhang, Electrochem. Comm., 8, 1173 (2006).

16. H. Oda and Y. Nakagawa, Carbon, 41, 1037 (2003).

17. S. Biloé, V. Goetz and A. Guillot, Carbon, 40, 1295 (2002).

18. V. K. Gupta and A. Rastogi, J. Hazard. Mater., 153, 759 (2008).

19. V. K. Gupta and A. Rastogi, J. Hazard. Mater., 152, 407 (2008).

20. V. K. Gupta, S. K. Srivastava, D. Mohan and S. Sharma, Waste Manag., 17, 517 (1997).

21. V. K. Gupta, I. Ali, V. K. Saini, T. V. Gerven, B. V. der Bruggen and C. Vandecasteele, Ind. Eng. Chem. Res., 44, 3655 (2005).

22. V. K. Gupta, C. K. Jain, I. Ali, S. Chandra and S. Agarwal, Water Res., 36, 2483 (2002).

23. K. Y. Foo and B. H. Hameed, Chem. Eng. J., 156, 2 (2010).

24. X. -J. He, T. Wang, J. -S. Qiu, X. -Y. Zhang, X. -T. Wang and M. -D. Zheng, New Carbon Mater., 26, 313 (2011).

25. A. P. Terzyk, Colloid. Surface. Physicochem. Eng. Aspect., 177, 23 (2001). 